\title{
Disturbance to brood-rearing Hooded Plover Thinornis rubricollis: responses and consequences
}

\author{
MICHAEL A. WESTON and MARK A. ELGAR
}

\section{Summary}

We examined the causes and consequences of disturbance to the chicks of Hooded Plover Thinornis rubricollis in central southern Victoria, Australia. Humans were the most frequent source of encounters, and response rates to a variety of stimuli were high. Three possible mechanisms by which disturbance could reduce chick survival were evaluated. (I) Disturbance might cause thermal stress to chicks. An encounter with a human often caused brooding to cease, but it is not clear whether overall levels of brooding were compromised. Chicks found themselves un-brooded due to disturbance for up to $290 \mathrm{~min}$, and in ambient temperatures of $10-46^{\circ} \mathrm{C}$. (2) Disturbance might cause energetic stress to chicks. Encounters with humans usually caused chick foraging to stop. Higher levels of disturbance were associated with less chick foraging. There was a tendency for broods to forage in lower and potentially more profitable levels of the habitat in less-disturbed conditions. However, the overall pattern of habitat use was similar during disturbed and less-disturbed conditions. (3) Adult defence of broods could be compromised by disturbance. However, no brood predation occurred in disturbed circumstances, and adults stayed close to their broods even in disturbed conditions. These data suggest that defence of chicks was not compromised by disturbance.

\section{Introduction}

The response of birds to the presence of a stimulus such as a potential predator or a human is referred to as "disturbance" (Fox and Madsen 1997). Many studies of disturbance report the effects of human activity on the combined survival of nests and young (e.g. Boellstorff et al. 1988). However, the response of birds to both potential predators and disturbance often varies with the stage of the breeding cycle (e.g. Simmons 1955, Watson 1988, Culik et al. 1995). Disturbance may be critical at some stages of the breeding cycle but not others (e.g. Heimberger et al. 1983, Götmark and Åhlund 1984, Watson 1988, Åhlund and Götmark 1989). This suggests that studies of disturbance should account for the stage of breeding.

Hooded Plover Thinornis rubricollis is a medium-sized plover endemic to southern Australia. Globally, the species is considered Near Threatened (BirdLife International 2000). In Australia, the eastern population is considered Vulnerable (Garnett and Crowley 2000). Given that populations are declining and relatively high chick mortality has been reported, it seems likely that chick survival plays an important role in population dynamics (Weston 2000). The beach habitat of this species constitutes a zone of intense recreational activity, and the interaction between humans and broods is thought to be a conservation problem (Schulz and Bamford 1987). The aim of this 
study was to describe the interaction between disturbance and brood-rearing Hooded Plovers and their chicks. Their response to disturbance is poorly known but an understanding of such interaction is required to determine whether chicks are detrimentally affected. Additionally, observational data were used to evaluate mechanisms through which disturbance could compromise chick survival. An understanding of how disturbance affects broods can be used to develop suitable management options.

The mechanisms thought most likely to link disturbance and chick survival in Hooded Plover are thermal stress and failure of defence (Schulz and Bamford 1987). An additional mechanism, energetic stress, may operate in other plovers (e.g. Burger 1991) and is also considered here (the mechanisms are not necessarily mutually exclusive). The proposed mechanisms are detailed below.

1. Thermal stress. Brooding of chicks serves to maintain their body temperature (Chappell 1980, O'Connor 1984, Visser and Ricklefs 1993a,b) and human disturbance may prevent plover chicks from being effectively brooded (Yalden and Yalden 1989, Burger 1991). Thermal stress is an oft-cited cause of disturbancerelated chick mortality (e.g. Burger 1981, Watson 1988, Yalden and Yalden 1989, 1990), but few studies have demonstrated the operation of this mechanism. If this mechanism operates on Hooded Plover chicks, we would expect to see decreased brooding with increasing levels of disturbance.

2. Failure of defence. Disturbance could cause failure of defence through spatial separation between defenders and their chicks, either by brood-scattering or by disturbance of the defenders. Alarm behaviour of brood-rearing plovers in response to humans may also attract predators (Yalden and Yalden 1989). Disturbance is implicated by increased predation rates of the young of some species following or in conjunction with disturbance (Åhlund and Götmark 1989, Keller 1991, Mikola et al. 1994). If this mechanism affects Hooded Plover chicks, we would expect decreased or compromised parental defence with higher levels of disturbance.

3. Energetic stress. Disturbance to plover chicks can also reduce foraging time or efficiency, or increase energy expenditure (Flemming et al. 1988, Burger 1991, Patterson et al. 1991, Lord et al. 1997, Goldin and Regosin 1998). Thus, disturbance may cause energetic stress in chicks. If this mechanism operates on Hooded Plover broods, we would expect to see either less foraging, a reduction in foraging efficiency, or foraging in sub-optimal habitats by disturbed Hooded Plover chicks.

In this study, we aimed to determine which mechanisms, if any, affect Hooded Plover broods. For each mechanism, we investigated whether the relevant response to disturbance occurs. Additionally, we determined what stimuli cause the response and whether Hooded Plovers discriminate between stimuli in terms of their response. Such information can place the response to human stimuli in context with the response to natural stimuli, and can inform management prescriptions. We then examined the effect of responses to assess whether the observed responses alter the quality of thermoregulation or defence, or the opportunity for effective foraging.

\section{Methods}

The study area consisted of ocean beaches from Johanna Beach, west of Cape Otway $\left(38^{\circ} 45^{\prime} \mathrm{S} 143^{\circ} 23^{\prime} \mathrm{E}\right)$, to Oberon Bay, Wilson's Promontory ( $\left.39^{\circ} \mathrm{O} 4^{\prime} \mathrm{S} 146^{\circ} 20^{\prime} \mathrm{E}\right)$, 
Victoria, Australia. This area was intensively searched from 1995 to 1998 (see Weston 2000). A repeated-measures sampling design was used to control for territory-specific and age-dependent factors. In this design, each brood was observed on a day of relatively high disturbance, a weekend day or public holiday, and again on a day of relatively low disturbance, often a non-public-holiday weekday. This choice of observation days aimed to maximize the difference in levels of disturbance between days. The number of human/brood encounters was significantly higher on the days designated as the high disturbance condition (83.9 \pm 64.7 encounters) compared with the days designated as the low disturbance condition (45.2 \pm 38.4 encounters; paired $t$-test on logged data, $t=-3.71, \mathrm{df}=8, P=0.006)$. Likewise, the days designated as high disturbance days had higher numbers of brood encounters with all stimuli (human and natural) (94.8 \pm 63.2 encounters) than days designated as low disturbance days $(53.5 \pm 42.3$ encounters; paired $t$-test, $t=-2.86, \mathrm{df}=8, P=0.021)$. The order of observations on relatively disturbed and undisturbed days was randomized for each brood. To qualify for use in the repeated-measures design, the two days of observations had to have similar (fine) weather conditions, be sequential or separated by no more than one day, and the brood size had to remain the same between observation days. Air temperature did not vary between relatively disturbed and undisturbed days (disturbed $21.7 \pm 3.7^{\circ} \mathrm{C}$, undisturbed $22.2 \pm 6.4^{\circ} \mathrm{C}$; Wilcoxon $\mathrm{Z}=0.296, P=0.767$ ).

In this study a 'stimulus' was any natural or human agent that had the potential to cause a response among breeding Hooded Plovers. An 'encounter' was any event where a stimulus passed within $100 \mathrm{~m}$ of a brood. The term 'multiple disturbance' described prolonged responses caused by repeated disturbances. 'Discrete disturbance' described circumstances where a bird ceased responding before another encounter occurred.

Adult responses to encounters were classified as 'no response' if there was no change in behaviour. If the adult left the chicks and remained at a distance and watched or false-fed then this was classified as a 'cryptic response'. If the bird left the chicks and was aggressive towards the potential predator it was classified as an 'aggressive response'. If the bird feigned injury, it was classified as a 'distraction response'. 'Leading' was a form of distraction that involved the adult(s) running ahead of a stimulus with tail and head down, stopping occasionally to false-brood. 'Chickleading' involved adult(s) running slowly in front of the chicks. 'Chick-searching' involved adult(s) calling, and running around the general area where the chicks had last been seen.

\section{Observations}

Broods were rare and few were located - the result of a rare species with high egg and chick mortality (Weston 2000). Brood observations were made on 26 days for 10-12 h each day, resulting in 18 days (nine pairs) that met the above conditions for the repeated-measures design. These pairs had at least one colour-banded adult allowing identification of particular pairs, and ensuring that each pair was sampled only once. Partial or complete brood loss between days of observation was the main reason for rejecting days of observation from the repeated-measures design.

During observations, activity scans were used to record the activity of adults and chicks every $5 \mathrm{~min}$. Each activity scan also recorded the habitat in which adults and chicks were located. Habitat was classified into five levels: (1) rock platforms; (2) lower beach, which had constant wave wash and was exposed between waves; (3) mid-beach, 
which was covered by the previous nocturnal tide and was flat and wet. Plovers tended to use the lower or upper margins of the mid-beach, thus the section was divided by eye into upper and lower halves; (4) upper beach, which was the area above the previous nocturnal high tide mark and was also divided by eye into upper and lower halves; and (5) foredunes and dunes, which began at the lowest beach vegetation or where there was a substantial change in slope (whichever occurred lower), and extended landward.

Continuous observations determined the response of chicks and attendant adults to passing stimuli. Encounters, and the level of habitat occupied by the stimulus, were recorded. The time between a disturbance and the resumption of normal chick activity was measured by timing the number of seconds between the start of the response and the time when the chick was detected standing or performing another non-hiding activity.

On 48 occasions, we approached chicks to measure and/or band them, and were able to note in detail the response of the adults to this activity.

Observations were also conducted to examine the value of the different levels of the habitat to foraging chicks in undisturbed circumstances (the only time when chicks foraged). 'Bill movements' were defined as any event where a chick's bill touched the substrate. The following data were recorded from foraging chicks: the time taken to make 10 bill movements, the number of those bill movements that were successful (when food was obtained), and the number of bill movements that penetrated into the substrate (i.e. probes). The level of the habitat in which foraging occurred was also recorded. Foraging events where the chicks ceased foraging due to disturbance or the occurrence of other non-foraging behaviours were excluded.

\section{Statistical analysis}

Chicks were only fitted with numbered metal bands, and so could not be individually recognized during observations. Thus, observational data on chicks are pooled within broods. Other procedures follow those outlined in Zar (1996).

The small sample sizes in this study meant the power of some statistical comparisons was likely to be low. Where statistical tests reported no difference between means or medians, the power and/or the required sample size was calculated using an effect size of $20 \%$ and an alpha level of $5 \%$. Power is the probability of correctly rejecting the null hypothesis. Low power reflects a high likelihood of incorrectly concluding that there was no effect. Thus, non-significant test results that are associated with low power should be interpreted cautiously - higher power associated with large sample sizes may reveal that a significant effect exists.

If the relatively undisturbed days of observation from the repeated-measures design are examined $(n=9)$, the only significant correlation between the proportion of chick observations of brooding, hiding and feeding (the main chick activities) is between brooding and hiding $(r=-0.70, P<0.05)$. Separate analyses for these parameters have been conducted, because disturbance may affect them differently, but it is recognized that these might not represent truly independent analyses.

\section{Results}

The main source of encounters with Hooded Plover broods were humans (81.1\%; Fig. 1). When disturbed, brood-rearing adults usually moved away from chicks, 


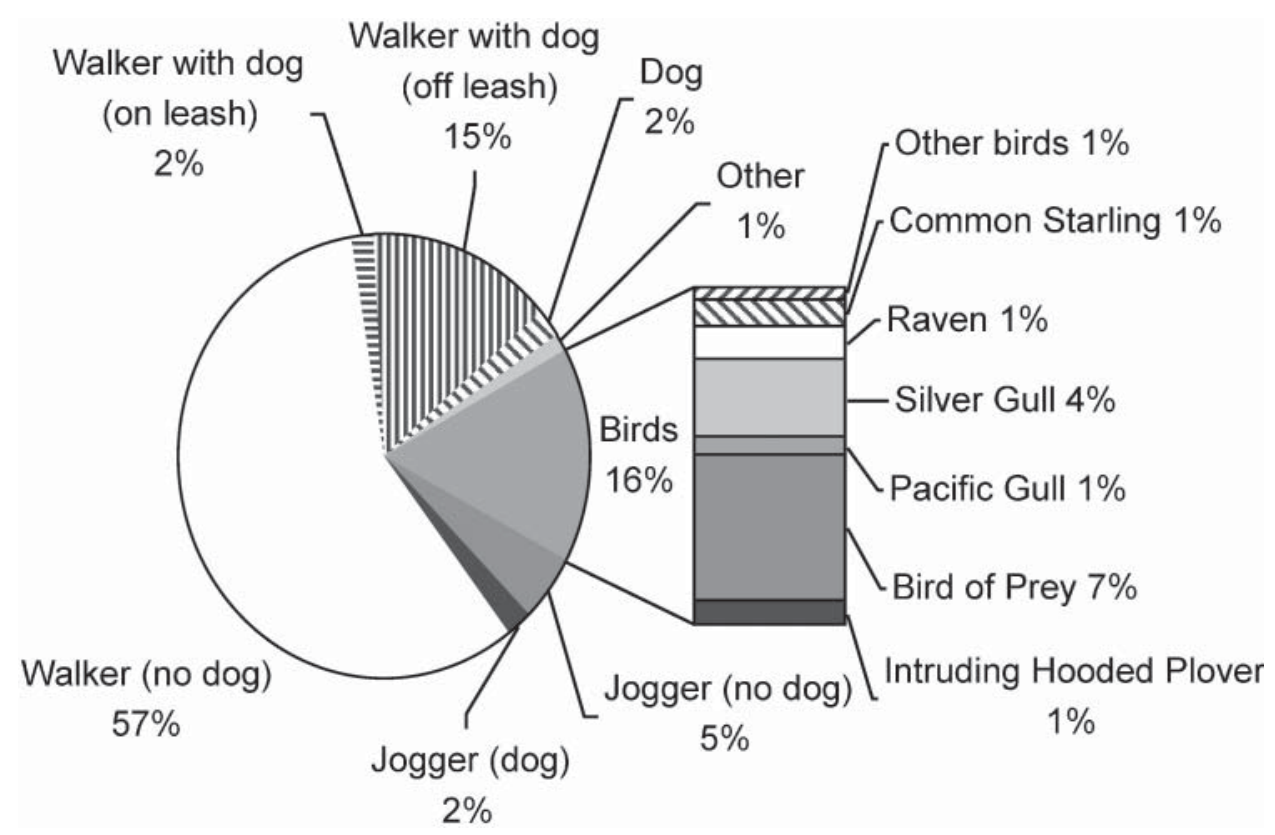

Figure 1. The contribution of different types of stimulus to encounters with Hooded Plover broods ( $n=1,510$ encounters). The breakdown of the encounters with birds is shown on the bar. The "other" category includes those stimuli that were encountered particularly infrequently.

and either retreated and watched, or used aggressive or distraction tactics. On some occasions, adults engaged in distinct chick-searching behaviour following a disturbance.

Only one type of response to encounters involved the adults approaching the chicks, albeit temporarily. In $3.5 \%$ of encounters, one $(27.8 \%)$ or both adults $(72.2 \%)$ led chicks away from a disturbance $(n=53)$. Chicks were typically led away from the water $(69.2 \%$ of leading events), and were never led to habitat levels nearer the water.

Brood-rearing adults spent considerable time responding to disturbance: $4.3 \%$ of the time being aggressive, $4.0 \%$ leading chicks, $3.5 \%$ searching for chicks after separation and $0.1 \%$ performing distraction displays (total $11.9 \%)(n=5,665$ observations of brood-rearing adults on 3,246 activity scans at territories with broods).

Chicks responded to disturbance by crouching and freezing. Overall, chicks hid for $33.3 \%$ of the time $(n=4,612$ observations). Chicks mostly hid in the foredune and dunes $(72.3 \% ; n=1,536$ observations, Fig. 2). Chicks often ran to nearby cover before hiding ( $43.6 \%$ of 493 occasions). In every encounter, chicks had the option of running up, down or along the beach. Of 215 incidents where broods ran then hid, they ran up the beach on $87.4 \%$ of occasions, remained in the same habitat level on $10.7 \%$ of occasions, and ran down the beach on $1.9 \%$ of occasions. Shorter runs were most common, with $51.6 \%$ of upward runs involving travel to the habitat level adjacent to and higher than the one where the chicks were originally located; $25.0 \%$ and $18.1 \%$ of runs took chicks two and three habitat levels higher respectively. The maximum number of habitat levels crossed during a run was six, but this only occurred once. On $82.8 \%$ of occasions when chicks ran then hid, they hid in the dunes. Of 14 encounters 


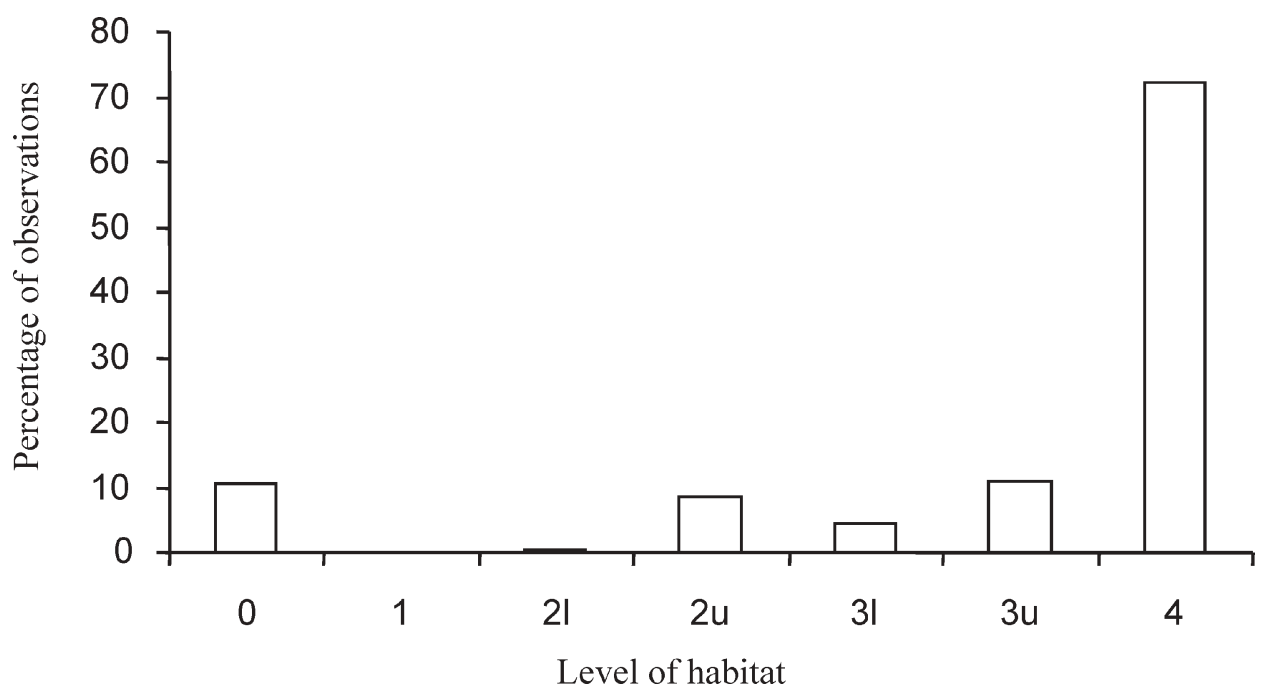

Figure 2. The distribution of Hooded Plover chicks hiding in different levels of the habitat ( $n=1,536$ observations of chicks hiding). Habitat levels are on the $\mathrm{x}$-axis: $\mathrm{O}$, rock platforms; 1 , lower beach; 2 l, lower half of mid-beach; $2 u$, upper half of mid-beach; 31 , lower half of upper beach; $3 u$, upper half of upper beach; and 4 , foredunes and dunes.

where the chicks were already in the dune, only once did the brood move onto the beach. On only three occasions did chicks run but not hide. Instead they stopped running high on the beach and watched.

Of 1,510 encounters, $63.1 \%$ were part of 177 multiple disturbances, where the chicks did not resume their normal activities before the next encounter occurred. In other words, $51.4 \%$ of encounters occurred while the chicks were already responding to other stimuli. In 149 of these multiple disturbances, we were able to determine the interval between the beginning of the response and the resumption of normal chick activities (21.3 $\pm 29.0 \mathrm{~min})$. The time the chicks spent hiding $\left(T_{\text {hider }} \mathrm{s}\right)$ increased with an increasing number of encounters in a series $\left(N_{\text {dists. }}\right)$ (linear regression, $\left.\log T_{\text {hide }}=0.933 \log N_{\text {dist. }}+5.411, F_{1,147}=143.95, P<0.001, R^{2}=0.495\right)$.

\section{Thermal stress}

Disturbance could cause thermal stress in chicks by disrupting brooding. Brooding adults often ceased brooding when an encounter occurred (Table I). It was uncommon for some chicks of a brood to continue to be brooded once brooding ceased for other chicks (only $3.4 \%$ of 117 observations). Overall, $49.1 \%$ of all encounters with brooding adults caused brooding to cease. Of 117 sessions of brooding that ended due to disturbance, $69.2 \%$ were ended by an encounter with humans. Of 261 brooding bouts recorded, $44.8 \%$ ended because of disturbance. Almost a third (31.0\%) of all brooding bouts observed were ended by an encounter with a human.

In order to examine whether brooding adults and chicks were discriminating between stimuli, the number of observed brooding cessations was compared with the expected number of cessations under the assumption that all stimuli had equal potential to cause brooding to cease (Table 2). Overall, observed frequencies did 
Table 1 . The response of brooding adults to different stimuli.

\begin{tabular}{|c|c|c|c|c|c|}
\hline Stimuli & $n$ & $\begin{array}{l}\% \text { of } \\
\text { encounters } \\
\text { that caused } \\
\text { brooding to } \\
\text { cease }\end{array}$ & $\begin{array}{l}\text { Average } \\
\text { duration until } \\
\text { normal chick } \\
\text { activity } \\
\text { resumed (min) }\end{array}$ & $\begin{array}{l}\text { SD of } \\
\text { duration until } \\
\text { normal chick } \\
\text { activity } \\
\text { resumed (min) }\end{array}$ & $\begin{array}{l}\text { Maximum } \\
\text { duration until } \\
\text { normal chick } \\
\text { activity } \\
\text { resumed (min) }\end{array}$ \\
\hline \multicolumn{6}{|l|}{ Human } \\
\hline Jogger(s) with dog & 3 & 100.0 & 1.9 & 1.6 & 3.0 \\
\hline Aircraft overflight & 3 & 66.7 & - & - & - \\
\hline Jogger(s) without dog & 12 & 58.0 & 7.0 & 2.6 & 10.0 \\
\hline Walker(s) with dog off leash & 35 & 51.4 & 6.8 & 8.7 & 28.0 \\
\hline Walker(s) without dog & 96 & 50.0 & 4.0 & 2.3 & 10.0 \\
\hline $\begin{array}{l}\text { Walker(s) with dog on leash } \\
\text { Non-human }\end{array}$ & 3 & $33 \cdot 3$ & - & - & - \\
\hline Fox ${ }^{a}$ & 1 & 100.0 & - & - & - \\
\hline Raven $^{\mathrm{b}}$ & 13 & 76.9 & 14.0 & 7.1 & 19.0 \\
\hline Pacific Gullc & 2 & 50.0 & - & - & - \\
\hline Intruding Hooded Plover & 5 & $45 \cdot 5$ & $3 \cdot 5$ & 0.7 & 4.0 \\
\hline Silver Gull ${ }^{\mathrm{d}}$ & 16 & 43.8 & 9.2 & $7 \cdot 7$ & 17.5 \\
\hline Bird of prey & 12 & 33.3 & - & - & - \\
\hline Common Starlinge & 11 & 0.0 & - & - & - \\
\hline
\end{tabular}

Frequency data are derived from those encounters where at least one adult was brooding. Duration data are taken from discrete encounters (i.e. not multiple disturbance). Thirteen events where brooding ceased due to unknown causes are excluded.

${ }^{a}$ Vulpes vulpes.

${ }^{\mathrm{b}}$ Corvus coronoides, C. tasmanicus and C. mellori.

'Larus pacificus.

${ }^{\mathrm{d}}$ Larus novaehollandiae.

eSturnus vulgaris.

not differ from expected frequencies (where expected frequencies exceeded five, $\chi^{2}=8.38, \mathrm{df}=6, P=0.212$, power $52.4 \%$ ).

Repeated-measures observations were collected from only seven broods where some brooding occurred. The proportion of observations during which chicks were brooded did not differ between relatively disturbed and undisturbed days $(23.0 \%$ and $27.1 \%$ respectively, Wilcoxon $Z=-0.676, P=0.499$ ). However, this test has low power $(12.5 \%)$; the samples sizes required to achieve power of $50 \%$ and $80 \%$ were 40 and 83 broods respectively.

The only activity during which chicks were apparently unable to solicit brooding was when they were hiding. The number of minutes chicks spent hiding per hour (pooled within broods) was significantly higher during relatively disturbed days (30.1 $\pm 15.6 \mathrm{~min})$ compared with relatively undisturbed days $(22.5 \pm 14.6 \mathrm{~min})$ (paired $t$-test, $t=2.613, \mathrm{df}=8, P=0.031$ ). For chicks less than 1 o days of age, the maximum duration of a hiding period was $245 \mathrm{~min}$. For chicks that had reached an age where they were no longer being brooded (at least diurnally), the maximum hiding duration recorded was $250 \mathrm{~min}$.

For discrete disturbances, the interval between the end of brooding and the resumption of non-hiding chick activity did not differ between human and non-human disturbances (overall, $6.7 \pm 10.3 \mathrm{~min}, t$-test on logged data, $t=0.77, \mathrm{df}=38.5$, $P=0.447 ; n=155$ intervals where the exact duration determined). However, the power of this test was low (12.0\%). 
Table 2. Observed and expected frequencies of disruption to chick brooding in response to encounters with different stimuli.

\begin{tabular}{|c|c|c|c|c|c|}
\hline \multirow[t]{2}{*}{ Stimuli } & \multicolumn{2}{|c|}{ Observed } & \multicolumn{2}{|c|}{ Expected } & \multirow[t]{2}{*}{ Partial chi-squared } \\
\hline & $n$ & $\%$ & $n$ & $\%$ & \\
\hline \multicolumn{6}{|l|}{ Human } \\
\hline Walker(s) without dog & 48 & 46.2 & 47.1 & $45 \cdot 3$ & 0.02 \\
\hline Walker(s) with dog off leash & 18 & $17 \cdot 3$ & 17.2 & 16.5 & 0.04 \\
\hline Jogger(s) without dog & 7 & 6.7 & $5 \cdot 9$ & $5 \cdot 7$ & 0.21 \\
\hline Jogger(s) with dog & 3 & 2.9 & 1.5 & 1.4 & \\
\hline Aircraft overflight & 2 & 1.9 & 1.5 & 1.4 & \\
\hline Walker(s) with dog on leash & 1 & 1.0 & 1.5 & 1.4 & \\
\hline \multicolumn{6}{|l|}{ Non-human } \\
\hline Raven & 10 & 9.6 & 6.4 & 6.1 & 2.03 \\
\hline Silver Gull & 7 & 6.7 & 7.8 & $7 \cdot 5$ & 0.08 \\
\hline Bird of prey & 4 & 3.8 & $5 \cdot 9$ & $5 \cdot 7$ & 0.61 \\
\hline Intruding Hooded Plover & 2 & 1.9 & 2.5 & 2.4 & \\
\hline Fox & 1 & 1.0 & 0.5 & 0.5 & \\
\hline Pacific Gull & 1 & 1.0 & 1.0 & 0.9 & \\
\hline Common Starling & o & 0.0 & $5 \cdot 4$ & 5.2 & 5.40 \\
\hline
\end{tabular}

Expected values are derived from the observed frequencies with which each stimulus category occurred, and assume an equal probability of causing brooding to cease. Sample sizes and percentage values refer to the number and percentage of brooding cessations respectively. The partial chi-squared value is shown where expected frequencies exceeded five.

Latin species names as in Table 1 .

\section{Energetic stress}

Disturbance could cause energetic stress to chicks by disrupting foraging, decreasing the efficiency of foraging, or by increasing energy expenditure. We observed 282 incidents where at least one chick in a brood was foraging at the time of an encounter (Table 3). There was no difference in the interval between interruption of foraging in chicks and the resumption of non-hiding behaviour between human and non-human disturbances $(8.2 \pm 14.0 \mathrm{~min}$ ) ( $t$-test on logged data, $t=1.30, \mathrm{df}=20.6, P=0.209$, power $25.4 \% ; n=72$ durations from discrete disturbances).

In order to examine whether foraging broods and their attendant adults were discriminating between stimuli, the number of observed disturbances was compared with the expected number of disturbances under the assumption that all stimuli had equal potential to cause foraging to cease (Table 4). Overall, observed frequencies differed from expected frequencies (where expected frequencies exceeded five, $\chi^{2}=14.13$, $\mathrm{df}=5, P=0.015)$, with the proportion of encounters that caused a response higher than expected for all stimuli except Silver Gulls and ravens. However, the significant difference was largely due to the lower than expected response rate to Silver Gulls which contributed $77.7 \%$ of the overall chi-squared value.

The time chicks spent foraging per hour (pooled within broods) was significantly higher on relatively undisturbed days $(19.4 \pm 8.5 \mathrm{~min})$ compared with relatively disturbed days (12.5 $\pm 6.4 \mathrm{~min}$ ) (paired $t$-test, $t=2.89, \mathrm{df}=8, P=0.020$ ).

For all encounters with foraging chicks, $86.2 \%$ resulted in cessation of foraging. Of 192 encounters between humans and feeding chicks, foraging ceased in $94.8 \%$ of encounters, and the proportion of encounters that caused foraging to cease was higher for encounters with humans than for encounters with non-human stimuli $(36.4 \%$ of non-human encounters caused foraging to cease; $n=33)\left(\chi^{2}=76.08, \mathrm{df}=1\right.$, 
Table 3. The response of feeding chicks to encounters with different stimuli.

\begin{tabular}{|c|c|c|c|c|c|}
\hline Stimuli & $n$ & $\begin{array}{l}\% \text { of } \\
\text { encounters } \\
\text { that caused } \\
\text { feeding to } \\
\text { cease }\end{array}$ & $\begin{array}{l}\text { Average } \\
\text { duration until } \\
\text { normal chick } \\
\text { activity } \\
\text { resumed (min) }\end{array}$ & $\begin{array}{l}\text { SD of } \\
\text { duration of } \\
\text { response } \\
\text { (min) }\end{array}$ & $\begin{array}{l}\text { Maximum } \\
\text { duration of } \\
\text { response (min) }\end{array}$ \\
\hline \multicolumn{6}{|l|}{ Human } \\
\hline Jogger(s) without dog & 11 & 100.0 & $5 \cdot 7$ & 4.0 & 10.0 \\
\hline Jogger(s) with dog & 3 & 100.0 & - & - & - \\
\hline Horse & 1 & 100.0 & 40.0 & - & 40.0 \\
\hline Walker(s) with dog off leash & 44 & $95 \cdot 5$ & 6.9 & 8.8 & 28.0 \\
\hline Walker(s) without dog & 125 & 94.4 & 8.8 & 17.0 & 110.0 \\
\hline $\begin{array}{l}\text { Walker(s) with dog on leash } \\
\text { Non-human }\end{array}$ & 8 & 87.5 & $5 \cdot 9$ & 5.8 & 10.0 \\
\hline Eastern Grey Kangaroo $^{a}$ & 2 & 100.0 & 14.0 & 11.3 & 22.0 \\
\hline Common Starling & 2 & 100.0 & 11.5 & - & 11.5 \\
\hline Australian Magpie ${ }^{b}$ & 1 & 100.0 & 74.0 & - & 74.0 \\
\hline Raven & 7 & 42.9 & - & - & - \\
\hline Silver Gull & 21 & 19.0 & 13.7 & $5 \cdot 3$ & $17 \cdot 5$ \\
\hline
\end{tabular}

Frequency data are derived from encounters with feeding chicks. Duration data are from discrete disturbances.

a Macropus giganteus.

${ }^{\mathrm{b}}$ Gymnorhina tibicen.

Other Latin species names as in Table 1 .

Table 4. Observed and expected frequencies of disruption to chick foraging in response to encounters with different stimuli.

\begin{tabular}{|c|c|c|c|c|c|}
\hline \multirow[t]{2}{*}{ Stimuli } & \multicolumn{2}{|c|}{ Observed } & \multicolumn{2}{|c|}{ Expected } & \multirow[t]{2}{*}{ Partial chi-squared value } \\
\hline & $n$ & $\%$ & $n$ & $\%$ & \\
\hline \multicolumn{6}{|l|}{ Human } \\
\hline Walker(s) without dog & 118 & 60.8 & 107.8 & 55.6 & 0.97 \\
\hline Walker(s) with dog off leash & 42 & 21.6 & $37 \cdot 9$ & 19.6 & 0.44 \\
\hline Jogger(s) without dog & 11 & $5 \cdot 7$ & $9 \cdot 5$ & 4.9 & 0.24 \\
\hline Walker(s) with dog on leash & 7 & 3.6 & 6.9 & 3.6 & 0.00 \\
\hline Jogger(s) with dog & 3 & 1.5 & 2.6 & 1.3 & \\
\hline Horse & 1 & 0.5 & 0.9 & 0.4 & \\
\hline \multicolumn{6}{|l|}{ Non-human } \\
\hline Silver Gull & 4 & 2.1 & 18.1 & $9 \cdot 3$ & 10.98 \\
\hline Raven & 3 & 1.5 & 6.0 & 3.1 & 1.50 \\
\hline Eastern Grey Kangaroo & 2 & 1.0 & 1.7 & 0.9 & \\
\hline Common Starling & 2 & 1.0 & 1.7 & 0.9 & \\
\hline Australian Magpie & 1 & 0.5 & 0.9 & 0.4 & \\
\hline
\end{tabular}

Expected frequencies are derived from the observed frequencies with which each stimulus category occurred, and assume an equal probability of causing foraging to cease. Sample sizes and percentage values refer to the number and percentage of foraging cessations respectively.

Latin species names as in Tables 1 and 3 .

$P<$ 0.001). The proportion of encounters with humans that caused a response was higher for encounters with foraging chicks than for encounters with chicks being brooded, where $51.7 \%$ of encounters with humans $(n=149)$ resulted in cessation of brooding $\left(\chi^{2}=83.04, \mathrm{df}=1, P<0.001\right)$. 
Table 5. The foraging behaviour of chicks in different habitat levels.

\begin{tabular}{lcccc}
\hline Parameter & Lower beach & Mid-beach & Upper beach & $\begin{array}{c}\text { Foredunes } \\
\text { and dunes }\end{array}$ \\
\hline$n$ (no. of foraging events recorded) & 3 & 128 & 93 & 41 \\
$n$ (no. of broods sampled) & 1 & 11 & 12 & 8 \\
Average time for 1o bill-movements (s) & 19.0 & 29.8 & 43.6 & 36.3 \\
\% of foraging events recording probes & 0.0 & 7.8 & 7.5 & 4.9 \\
\% of foraging events recording successes & 100.0 & 73.5 & 52.4 & 18.8 \\
Maximum no. of probes in a foraging event $^{\mathrm{a}}$ & 0 & 9 & 4 & 1 \\
Maximum no. of successes in a foraging event $^{\mathrm{a}}$ & 5 & 4 & 3 & 1 \\
\hline
\end{tabular}

${ }^{\mathrm{a}}$ Maximum possible is 10.

In addition to impeding energy intake due to interrupted foraging, at least one response of the chicks (the run and hide response) was probably energetically expensive. The hourly rate of this response did not differ between days of relatively high and low disturbance (1.2 \pm 0.9 and $1.0 \pm 0.9$ respectively, Wilcoxon $Z=-0.676$, $P=0.499)$ but power was low (13.1\%).

Disturbance could displace chicks from favoured foraging habitat. A prerequisite for habitat displacement to compromise foraging efficiency is that chicks have different foraging efficiencies in different levels of the habitat. Although we collected data from 265 chick foraging events, statistical comparison of foraging behaviour in different habitat levels was not possible due to problems with the independence of the data points and because no brood was represented in all habitat levels. As an alternative, summary statistics are presented (Table 5). There are some indications that the lower areas of the beach are more profitable feeding sites. The average time to make to bill movements increased with higher levels of the habitat. The proportion of successful foraging events, and the maximum number of successes in a foraging event, decreased in higher levels of the habitat.

There was a strong tendency for chicks to forage over more habitat levels on days of relatively low disturbance (median of three levels) compared with days of relatively high disturbance (median of two levels) (Wilcoxon $Z=1.947, P=0.052 ; n=9$ ).

On days of lower disturbance, foraging chicks ventured to habitat levels lower than were reached during relatively disturbed days (Fig. 3). Higher habitat levels were used more on disturbed days. However, most chick foraging occurred in the midbeach regardless of disturbance levels. This suggests that displacement did not prevent use of the preferred foraging level.

\section{Failure of defence}

Disturbance could compromise defence of the brood by separating chicks from their defending parents, but a prerequisite for this mechanism is that the parents defend their chicks. Active defence (distraction, leading and aggression) was employed in $11.2 \%$ of encounters. Distraction displays (injury feigning) were used infrequently and were given in only $1.0 \%$ of encounters (but in $29.2 \%$ of $n=48$ investigator approaches). Distraction displays were given at the same rate to human and natural stimuli $\left(\chi^{2}=0.04, \mathrm{df}=1, P=0.839\right)$, but the power of this test was low $(5.5 \%)$. Because broods encountered humans more frequently than natural stimuli (Fig. I), 


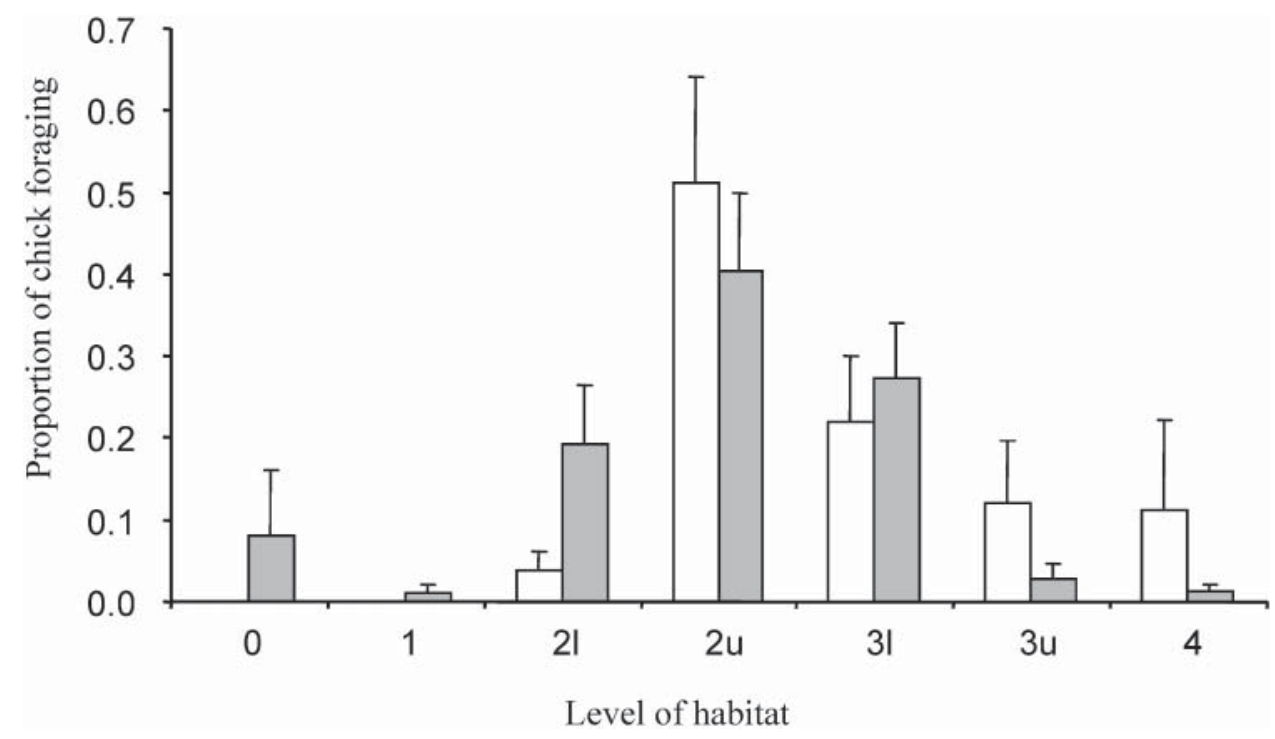

Figure 3. Habitat use by foraging Hooded Plover chicks on days of relatively high and low disturbance. Means (+ SE) of the proportion of chick foraging that occurred in each habitat level are shown ( $n=9$ repeated-measures broods). A key to habitat levels on the $x$-axis is provided in the legend to Fig. 2. Shaded bars indicate relatively less disturbed conditions and non-shaded bars indicate relatively disturbed conditions.

distraction displays were mostly given to humans $(80.0 \%)$. Overall, distraction displays were given during $1.4 \%$ of encounters involving humans with dogs, compared with $0.9 \%$ of encounters with humans alone, but data were too few for statistical comparison.

Of the 15 observed encounters that resulted in distraction displays, seven involved both adults displaying $(46.7 \%)$. In $78.6 \%$ of investigator approaches in which a distraction display occurred and details were noted $(n=14)$, both attendant adults gave a distraction display. There was no difference in the proportion of distraction displays involving both adults between encounters and investigator approaches $\left(\chi^{2}=1.92\right.$, $\mathrm{df}=1, P=0.166$, power $28.3 \%$ ).

Leading was used in $4.6 \%$ of encounters (6.3\% of $n=48$ investigator approaches). Leading was predominantly used in encounters with humans (95.6\% of $n=69$ leading events), and was never used in encounters with other birds. Leading was always in the same direction as the movement of the stimulus, generally along the beach parallel to the water's edge. At the end of a leading event, adults were in the same habitat level as the level in which they began on $71.2 \%$ of occasions ( $n=66$ leading events where habitat was noted); otherwise they ended up higher on the beach. On $30.4 \%$ of occasions when leading occurred $(n=69)$ a single adult led, otherwise both led.

Adults used aggression in $5.8 \%$ of encounters. Of 50 discrete encounters that caused aggression, most were directed at other birds ( $96.0 \%$ of encounters causing aggression), particularly gulls $(62.0 \%)$ and intruding conspecifics $(22.0 \%)$, but small passerines $(8.0 \%)$, corvids $(2.0 \%)$ and raptors $(2.0 \%)$ also elicited an aggressive response; $4.0 \%$ of encounters that evoked aggression involved walkers without dogs. On $58.0 \%$ of occasions where aggression was used, both pair members were involved. 
All defensive behaviour required the presence of the adults near the brood. There was no difference in the average number of parents in view per activity scan on days of relatively high and low disturbance (overall, $1.80 \pm 0.24$ parents per scan, Wilcoxon $Z=0.701, P=0.483 ; n=9$; power $44.5 \%$ ). However, the lengthy periods of chick hiding caused by disturbance might have resulted in adults losing track of the exact position of their brood, which could be important for effective brood defence. The percentage of adult observations that involved chick-searching was significantly higher on relatively disturbed days (6.1\% of observations) than on relatively undisturbed days (2.0\%, Wilcoxon $Z=-2.547, P=0.011 ; n=9)$. Nevertheless, no chick was permanently lost during observations.

The adult defensive responses combined with the cryptic response of chicks was apparently very effective at enabling chicks to avoid detection. Of 2,246 humans that passed broods, only one group (o.1\% of all humans) located one chick from a brood of three. Of 334 dogs that passed broods (90.1\% were unleashed and so free to roam), none located a chick. Of 114 raptors that passed broods, only one obviously detected a brood, and killed a chick (0.9\%). In $271 \mathrm{~h}$ of observations of broods, including 261 encounters with potential predators (not humans or intruding Hooded Plovers), defence of the brood failed once, and this occurred during an undisturbed period.

\section{Discussion}

This study can offer no unequivocal evidence linking levels of disturbance with reduced chick survival in Hooded Plover. Nevertheless, the data reveal that disturbance reduces feeding and disrupts brooding of chicks, influences that might reduce chick survival. Reduced foraging and brooding due to disturbance are thought to be responsible for decreased chick survival in the ecologically and behaviourally similar Piping Plover Charadrius melodus (Flemming et al. 1988, Strauss and Dane 1989, Burger 1991, Melvin et al. 1991, Patterson et al. 1991, Loegering and Fraser 1995, Goldin and Regosin 1998). Thus, the reductions in brooding and feeding reported here are likely to compromise chick survival in Hooded Plover.

\section{Response}

Hooded Plovers cease brooding when stimuli approach, leaving the cryptic chicks to hide. This strategy is effective at keeping chicks undetected by humans and potential predators, but means that brooding is frequently interrupted. Brood-rearing Hooded Plovers used a range of behaviours to respond to different stimuli which have been described for other brood-rearing shorebirds (e.g. Wilcox 1959, Graul 1975, Pienkowski 1984, Yalden and Yalden 1989, Yalden 1992).

Hooded Plover chicks commonly freeze when they encounter a stimulus, a response common among shorebirds, and which is also used in response to human intrusion (e.g. Simmons 1955, Wilcox 1959, Pienkowski 1984, Yalden and Yalden 1990, Yalden 1992). They often moved up the beach and into the dunes before hiding, probably allowing them to locate themselves in microhabitats that provide favourable protection from predators and thermal extremes (Burger and Gochfeld 1990, Sordahl 1991, Burness and Morris 1992, Visser and Ricklefs 1993a, Brown and Morris 1994). Such use of cover may explain the lengthy periods that Hooded Plover chicks can hide in the dunes un-brooded (up to $250 \mathrm{~min}$ ), in comparison with other wader chicks in other environments (up to $34 \mathrm{~min}$ for Common Sandpiper Actitis hypoleucos chicks; 
Yalden and Yalden 1990, Yalden 1992). The heavy reliance of Hooded Plover chicks on the dunes and foredunes as the main site of concealment emphasizes the importance of dune systems in the habitat of this species. Even beach-nesting pairs hide their chicks in the dunes, and so all coastally breeding Hooded Plovers use foredunes and dunes during the breeding cycle.

The high response rate of foraging chicks and brooding adults to a variety of stimuli suggests that habituation during the brood-rearing phase is at best minimal. Humans were responsible for over $80 \%$ of encounters, and were the predominant cause of disrupted brooding and chick foraging. We expect that those parts of the coast with high numbers of humans will also be those where brood-rearing will be most disrupted. Thus, managing humans will go a long way to managing disturbance to broods.

\section{Thermal stress}

Young shorebird chicks rely more upon parental sources of heat than on their own thermogenesis to regulate their body temperature. The degree of homeothermy is positively correlated with body mass among shorebird neonates (Chappell 1980, Visser and Ricklefs 1993a,b). At an average of $9.2 \mathrm{~g}$ at hatching, Hooded Plover chicks are among the smaller shorebird neonates (see Weston 2000). Hooded Plover chicks are therefore expected to have difficulty maintaining their body temperature without parental assistance, and disruption of brooding is likely to interfere with thermoregulation. In this study, chicks hid from disturbance (and so were not brooded) over the entire range of ambient temperatures recorded for broods $\left(10-46^{\circ} \mathrm{C}\right)$. Thus, the potential for disturbance-induced thermal stress in Hooded Plover chicks seems high.

Although disturbance interrupted brooding in Hooded Plovers, overall rates of brooding did not significantly decrease on relatively disturbed days compared with relatively undisturbed days. Low statistical power may be one possible reason for the lack of a statistically significant difference. In the current study area at least, achieving even the modest power of $50 \%$ seems impractical because it would require data collection over an additional 10.3 breeding seasons. In studies of disturbance to rare species, population size can preclude the attainment of adequate levels of statistical power (Delaney et al. 1999). Under such circumstances, readily measurable inferential behavioural data may be the only practical indication as to the existence of a mechanism. This study shows that disturbance frequently disrupts brooding, sometimes causing normal chick activity to cease for substantial periods. Thus, even in the absence of high statistical power, it is clear that disturbance disrupts brooding.

No direct information is available on the lethal thermal limits for Hooded Plover chicks, or on the temperatures they experienced during disturbance. Even 3-4 min disruptions to brooding which occurs in alternate $7-8$ or 10-12 min bouts, could be a serious risk to the survival of wader chicks (Yalden and Yalden 1990, Yalden 1992). We regularly recorded longer disruptions to brooding, but never recorded the death of a chick that could be attributed to thermal stress. On a highly disturbed day, a brood in their third day of life was not brooded for $290 \mathrm{~min}$ - one of these chicks survived to fledge. Shorebird chicks show high thermal tolerances, possibly as an adaptation to promote efficient self-feeding (Myhre and Steen 1979, Chappell 1980, Visser and Ricklefs $1993 a, b)$, and it may be useful in areas where disturbance to chicks is frequent (Pienkowski 1984). Nevertheless, human disturbance can cause extremes in the body temperature of chicks (see Norton 1973). 
Two features of recreational behaviour possibly minimize the effect of disturbance on the thermoregulation of chicks. Firstly, a typically diurnal pattern in the number of recreationists on beaches (pers. obs.) means most disturbance to broods is likely to occur during the middle of the day when, even under minimally disturbed conditions, little brooding occurs (Weston 2000). Secondly, heavily disturbed days are probably warmer days. Plover chicks are known to avoid overheating by using shade and keeping off heated substrate (Graul 1975, Wolcott and Wolcott 1999). Both these thermoregulatory mechanisms are compatible with hiding in the dunes.

\section{Energetic stress}

Decreased foraging with increased disturbance is reported for shorebird broods (e.g. Flemming et al. 1988, Burger 1991, Lord et al. 1997). Encounters with foraging Hooded Plover chicks often caused foraging to cease and encounters with humans almost always ended foraging. Thus, chicks spent less time foraging on relatively disturbed days. There is a positive correlation between foraging time and survival of wader chicks (Flemming et al. 1988, Beintema and Visser 1989, Patterson et al. 1991, Wolcott and Wolcott 1999). Consequently, decreased energy intake could be a mechanism through which disturbance reduces Hooded Plover chick survival.

Broods can be displaced by disturbance (e.g. Heimberger et al. 1983, Yalden 1992, Lord et al. 1997, Wolcott and Wolcott 1999). Such displacement could be critical if different habitats represented differential profitability to foraging chicks (Burger 1991). We found disturbance caused minor displacement in the level of the habitat where the chicks fed, and there is some evidence that chicks were displaced away from the most profitable foraging habitat. Despite being displaced by disturbance, foraging chicks still concentrated their foraging in the preferred habitat levels.

The energetic costs of avoiding disturbance may contribute to mortality in young birds (Mikola et al. 1994, see Loegering and Fraser 1995). Hooded Plover chicks frequently ran from humans - presumably an energetically costly response. In addition to energy expended in active responses to disturbance, internal responses may also be energetically costly (e.g. Regel and Pütz 1997). However, Hooded Plover chicks almost always end up crouching and freezing. These are behaviours associated with decreased heart and respiration rates in at least in some birds (Gabrielsen et al. 1977, 1985). No study has calculated the energetic cost to wader chicks of their response to disturbance (O'Connor 1984, Yalden and Yalden 1990), but it may be considerable.

The energetic and thermal stress mechanisms may interact. When responding to threats, chicks neither feed nor are they brooded (Pienkowski 1984, Yalden and Yalden 1990, Yalden 1992). Even when precocial young birds are able to maintain body temperature in cold conditions, they expend more energy doing so compared with young that are able to solicit parental warming (Visser and Ricklefs 1993a,b, Espira and Evans 1996). When chilled, food-stressed precocial chicks are unable to achieve homeothermy, unlike well-fed conspecifics (Harun et al. 1997).

\section{Failure of defence}

Hooded Plover adults, like those of other plovers (e.g. Wilcox 1959, Pienkowski 1984), play an important role in chick defence. Disturbance can compromise the antipredator defence of pre-fledged birds (e.g. Åhlund and Götmark 1989, Mikola et al. 1994). Where both parents defend the brood, the presence of both adults on the territory 
could be essential for adequate defence (Burger 1991). Disturbance did not reduce the amount of time Hooded Plover adults spent in the vicinity of the brood, suggesting disturbance did not affect the potential for parental defence (but power was only moderate). The increase in chick-searching behaviour in disturbed conditions suggests some diminution in the quality of information available to the adults regarding brood location, but the importance of this to effective defence is unknown. Nevertheless, Hooded Plovers avoid brood predation in the vast majority of encounters with potential predators, despite high overall levels of disturbance. This suggests disturbance does not compromise the antipredator defence of Hooded Plover chicks.

\section{Recommendations for management and further research}

This study suggests that management of disturbance to broods is warranted. There is a range of management tools that could be applied. Perhaps the most promising management technique is the use of artificial chick shelters. These could potentially reduce the effects of thermal stress by providing sheltered hiding places. By placing the shelters at different levels of the beach, chicks could hide nearer their favoured foraging zones, potentially reducing the energy required to respond to disturbance, and possibly shortening the duration of disruptions to foraging. Other benefits include protection from predators and inadvertent crushing by humans (Weston 2003).

In terms of research, there is an urgent need to determine the causes of chick mortality, to ensure that all important threats have been identified. The effectiveness of the potential management techniques, especially chick shelters, also needs to be studied. In this way, their use can be tested and refined, and the limited resources available for managing such a highly dispersed species can be used to optimal effect (Weston 2003).

\section{Acknowledgements}

This research was conducted under Department of Natural Resources and Environment permits (RP97208, RP96113 and RP95067), Parks Victoria permits (NP978/095, NP945/156 and NP67/O11), Ethics Approval Permit (AEEC 6540720921120) and appropriate Australian Bird and Bat Banding Scheme (ABBBS) permits. Financial support was provided by an Australian Postgraduate Research Award, the Holsworth Wildlife Research Fund, the Australian Bird Environment Foundation, Barwon Heads Committee of Management, the M. A. Ingram Trust and the Stuart Leslie Bird Research Fund (Birds Australia). Drs M. A. Giese, D. P. Hart, W. Sutherland and J. Burger kindly commented on a PhD thesis chapter upon which this paper is based.

A. H. Burbidge and S. Buckton kindly reviewed and edited the manuscript.

\section{References}

Åhlund, M. and Götmark, F. (1989) Gull predation on Eider Ducklings Somateria mollissima: effects of human disturbance. Biol. Conserv. 48: 115-127.

Beintema, A. J. and Visser, G. H. (1989) Growth parameters in chicks of Charadriiform birds. Ardea 77: 169-181.

BirdLife International (2000) Threatened birds of the world. Barcelona and Cambridge, U.K.: Lynx Edicions and BirdLife International. 
Boellstorff, D. E., Anderson, D. W., Ohlendorf, H. M. and O'Neill, E. J. (1988) Reproductive effects of nest-marking studies in an American White Pelican colony. Colonial Waterbirds 11: 215-219.

Brown, K. M. and Morris, R. D. (1994) The influence of investigator disturbance on the breeding success of Ring-billed Gulls (Larus delawarensis). Colonial Waterbirds 17: 7-17.

Burger, J. (1981) Effects of human disturbance on colonial species, particularly gulls. Colonial Waterbirds 4: 28-36.

Burger, J. (1991) Foraging behaviour and the effect of human disturbance on the Piping Plover (Charadrius melodus). J. Coastal Res. 7: 39-52.

Burger, J. and Gochfeld, M. (1990) Early experience and vegetation preferences in Common Tern chicks. Wilson Bull. 102: 328-333.

Burness, G. P. and Morris, R. D. (1992) Shelters decrease gull predation on chicks at a Common Tern colony. J. Field Ornithol. 63: 186-189.

Chappell, M. A. (1980) Thermal energetics of chicks of Arctic-breeding shorebirds. Comp. Biochem. Physiol. 65A: 311-317.

Culik, B., Adelung, D. and Woakes, A. J. (1995) Penguins disturbed by tourists. Nature 376: 301.

Delaney, D. K., Grubb, T. G., Beier, P., Pater, L. I. and Reiser, M. H. (1999) Effects of helicopter noise on Mexican Spotted Owls. J. Wildl. Manag. 63: 6o-76.

Espira, A. and Evans, R. M. (1996) Energy savings from vocal regulation of ambient temperature by 3-day-old domestic chicks. Can. J. Zool. 74: 599-605.

Flemming, S. P., Chiasson, R. D., Smith, P. C., Austin-Smith, P. J. and Bancroft, R. P. (1988) Piping Plover status in Nova Scotia related to its reproductive and behavioural responses to human disturbance. J. Field Ornithol. 59: 321-330.

Fox, A. D. and Madsen, J. (1997) Behavioural and distributional effects of hunting disturbance on waterbirds in Europe: implications for refuge design. J. Appl. Ecol. 34: 1-13.

Gabrielsen, G., Kanwisher, J. and Steen, J. B. (1977) "Emotional" bradycardia: a telemetry study on incubating Willow Grouse (Lagopus lagopus). Acta Physiol. Scand. 10o: 255-257.

Gabrielsen, G. W., Blix, A. S. and Ursin, H. (1985) Orienting and freezing responses in incubating Ptarmigan hens. Physiol. Behav. 34: 925-934.

Garnett, S. T. and Crowley, G. (2000) The action plan for Australian birds. Canberra: Environment Australia.

Goldin, M. R. and Regosin, J. V. (1998) Chick behaviour, habitat use, and reproductive success of Piping Plovers at Goosewing Beach, Rhode Island. J. Field Ornithol. 69: 228-234.

Götmark, F. and Åhlund, M. (1984) Do field observers attract nest predators and influence nesting success of Common Eiders? J. Wildl. Manag. 48: 381-387.

Graul, W. D. (1975) Breeding biology of the Mountain Plover. Wilson Bull. 87: 6-31.

Harun, M. A. S., Van Kampen, K. M., Veeneklaas, R. J., Huisman, G. H. and Visser, G. H. (1997) Food restriction and development of thermoregulation in Muscovy ducklings (Cairina moschata). Br. Poultry Sci. 38: 381-389.

Heimberger, M., Euler, D. and Barr, J. (1983) The impact of cottage development on Common Loon reproductive success in central Ontario. Wilson Bull. 95: 431-439.

Keller, V. E. (1991) Effects of human disturbance on Eider ducklings Somateria mollissima in an estuarine habitat in Scotland. Biol. Conserv. 58: 213-228.

Loegering, J. P. and Fraser, J. D. (1995) Factors affecting Piping Plover chick survival in different brood-rearing habitats. J. Wildl. Manag. 59: 646-655.

Lord, A., Waas, J. R. and Innes, J. (1997) Effects of human activity on the behaviour of northern New Zealand Dotterel Charadrius obscurus aquilonius chicks. Biol. Conserv. 82: 15-20.

Melvin, S. M., Griffin, C. R. and MacIvor, L. H. (1991) Recovery strategies for Piping Plovers in managed coastal landscapes. Coastal Manag. 19: 21-34.

Mikola, J., Miettinen, M., Lehikoinen, E. and Lehtilä, K. (1994) The effects of disturbance caused by boating on survival and behaviour of Velvet Scoter Melanitta fusca ducklings. Biol. Conserv. 67: 119-124. 
Myhre, K. and Steen, J. B. (1979) Body temperature and aspects of behavioural temperature regulation in some neonate Subarctic and Arctic birds. Ornis Scand. 10: 1-9.

Norton, D. W. (1973) Ecological energetics of Calidrine sandpipers breeding in Northern Alaska. Unpublished PhD thesis, University of Alaska, U.S.A.

O'Connor, R. J. (1984) The growth and development of birds. Chichester, U.K.: Wiley.

Patterson, M. E., Fraser, J. D. and Roggenbuck, J. W. (1991) Factors affecting Piping Plover productivity on Assateague Island. J. Wildl. Manag. 55: 525-531.

Pienkowski, M. W. (1984) Behaviour of young Ringed Plovers Charadrius hiaticula and its relationship to growth and survival to reproductive age. Ibis 126: 133-155.

Regel, J. and Pütz, K. (1997) Effect of human disturbance on body temperature and energy expenditure in penguins. Polar Biol. 18: 246-253.

Schulz, M. and Bamford, M. (1987) The Hooded Plover - an RAOU conservation statement. Royal Australasian Ornithologists Union (Birds Australia) Report 35.

Simmons, K. E. L. (1955) The nature of the predator-reactions of waders towards humans; with special reference to the role of the aggressive-, escape- and brooding-drives. Behavior 8: $130-169$.

Sordahl, T. (1991) Antipredatory behaviour of Mountain Plover chicks. Prairie Nat. 23: 109-115.

Strauss, E. and Dane, B. (1989) Differential reproductive success in a stressed population of Piping Plovers in areas of high and low human disturbance. Am. Zool. 29: 42A.

Visser, G. H. and Ricklefs, R. E. (1993a) Temperature regulation in neonates of shorebirds. Auk I10: 445-447.

Visser, G. H. and Ricklefs, R. E. (1993b) Development of temperature regulation in shorebirds. Physiol. Zool. 66: 771-792.

Watson, A. (1988) Dotterel Charadrius morinellus numbers in relation to human impact in Scotland. Biol. Conserv. 43: 245-256.

Weston, M. A. (2000) The effect of disturbance on the breeding biology of Hooded Plovers. Unpublished PhD thesis, University of Melbourne, Victoria.

Weston, M. A. (2003) Managing the Hooded Plover in Victoria - a review of existing information. Parks Victoria Technical Series No. 4.

Wilcox, L. (1959) A twenty year banding study of the Piping Plover. Auk 76: 129-153.

Wolcott, D. L. and Wolcott, T. G. (1999) High mortality of Piping Plovers on beaches with abundant Ghost Crabs: correlation, not causation. Wilson Bull. 111: 321-329.

Yalden, D. W. (1992) The influence of recreational disturbance on Common Sandpipers Actitis hypoleucos breeding by an upland reservoir, in England. Biol. Conserv. 61: 41-49.

Yalden, D. W. and Yalden, P. E. (1989) The sensitivity of breeding Golden Plovers Pluvialis apricaria to human intruders. Bird Study 36: 49-55.

Yalden, P. E. and Yalden, D. W. (1990) Recreational disturbance of breeding Golden Plovers Pluvialis apricarius. Biol. Conserv. 51: 243-262.

Zar, J. H. (1996) Biostatistical analysis. New Jersey: Prentice Hall International.

\section{MICHAEL A. WESTON}

Department of Zoology, University of Melbourne, Parkville, Victoria 3052, Australia.

Current address: Birds Australia, 415 Riversdale Road, Hawthorn East, Victoria 3123, Australia.E-mail:m.weston@birdsaustralia.com.au

MARK A. ELGAR

Department of Zoology, University of Melbourne, Parkville, Victoria 3052, Australia.

Received 19 January 2004; revision accepted 8 October 2004 